\title{
O Alinhamento Estratégico e a Construção do Futuro: um Estudo Exploratório
}

\author{
A. Roberto R. Nogueira \\ Paula C. A. Moreira
}

\section{RESUMO}

O objetivo desse trabalho é apresentar, pela primeira vez no Brasil, uma pesquisa exploratória que analisa o direcionamento para o futuro, de acordo com os conceitos de Prahalad e Hamel (1990), e sua associação com os processos de alinhamento estratégico, de recursos humanos e de tecnologia de informação. Para tal foram operacionalizados os conceitos de direcionamento para o futuro, o de formalização do processo de planejamento, o de alinhamento estratégico da área de tecnologia de informação e o de alinhamento da área de recursos humanos. O estudo permite a análise de cada uma das variáveis acima descritas, tanto em relação a sua confiabilidade e validade, como também através de análises fatoriais. De acordo com a literatura revista no trabalho, foi proposta a pergunta da pesquisa: de que forma o grau de formalização do processo de planejamento das empresas, o grau de alinhamento da área de tecnologia de informação e da área de recursos humanos influenciam o direcionamento para o futuro das empresas ? Foram montadas três hipóteses, de acordo com um modelo de path-analysis, permitindo a análise das correlações parciais entre as variáveis estudadas.

Palavras-chaves: planejamento estratégico; tecnologia da informação; competição; gestão de recursos humanos.

\begin{abstract}
This survey analyses the influence of the Planning Process, the Strategic Alignment of IT and Human Resources on the awareness of the companies towards the Competition for the Future. During the period covered by this research Brazil was in a process of economic stabilization after years of high inflation, with increased opening to foreign competition, which stressed the need for effective planning at the corporate level. The results of the analysis of our survey data show that the companies Information Technology, Human Resources and Planning Process strategies and policies were not adequately oriented toward helping them compete for the future.
\end{abstract}

Key words: strategic planning; information technology; competition; human resources management. 


\section{INTRODUÇÃO}

À medida que o mundo integra seus mercados e que a competição se torna um fenômeno de escala mundial, as empresas necessitam observar quais fatores deveriam ser levados em conta para maximizar suas chances de sucesso e sobrevivência, não só no curto prazo, mas principalmente em um horizonte mais distante.

No início dessa década, Prahalad e Hamel (1990), em trabalho seminal, analisam a questão competitiva em uma ótica de longo prazo, através da comparação de casos de sucesso e fracasso de negócios em escala mundial. Com a posterior publicação de seu livro, Hamel e Prahalad (1994) verificam os conceitos e as práticas de planejamento empresarial para que seja possível a construção do futuro.

O objetivo desse trabalho é apresentar, pela primeira vez no Brasil, uma pesquisa exploratória que analisa o direcionamento para o futuro, de acordo com os conceitos de Prahalad e Hamel (1990), e sua associação com os processos de alinhamento estratégico, de recursos humanos e de tecnologia de informação.

Dessa forma, é apresentada uma sucinta revisão da literatura sobre esses temas, seguida pelos resultados da pesquisa e uma breve conclusão.

\section{Alinhamento Estratégico}

Estratégia, segundo Quinn (1991), é um padrão ou plano que integra, de forma coesa, os principais objetivos, políticas e ações de uma organização.

As principais dimensões de uma estratégia são as seguintes:

. conter os mais importantes objetivos, as mais significativas políticas e as mais importantes ações a serem executadas;

. ser concebida através de um pequeno conjunto de conceitos e forças, que the dão coesão, equilíbrio e foco;

. lidar tanto com os imprevistos quanto com o desconhecido. A essência da estratégia é a construção de uma postura que, embora potencialmente flexível, seja tão forte em seletividade, que permita a organização atingir seus objetivos a despeito da ação imprevista ou desconhecida de forças externas; 
. possuir uma hierarquia, principalmente no caso de organizações complexas.

Ainda segundo o autor, uma estratégia eficaz deverá apresentar as seguintes características:

. apresentar objetivos claros e decisivos;

. promover a iniciativa, preservando a liberdade de ação e aumentando o comprometimento;

. concentrar força e poder no momento e local crucial;

. prover flexibilidade, através da construção de reservas de recursos;

. coordenar e comprometer a liderança;

. surpreender os competidores;

. prover segurança para a base de recursos do negócio.

Andrews (1991) aprofunda o conceito de estratégia e fornece um quadro de referência para a sua análise. Ele define estratégia como sendo um padrão de decisões que determinam e revelam seus objetivos, produzem as principais políticas e planos, identificam o segmento de negócio no qual a empresa está, o tipo de organização econômica e humana que ela é, ou pretende ser, e a natureza das contribuições econômicas e não-econômicas a serem oferecidas aos acionistas, empregados, clientes e à comunidade.

Em seu modelo, divide o processo estratégico em duas etapas:

. Formulação da Estratégica (decisão do que fazer):

. identificação de oportunidades e riscos;

. determinação dos recursos:

. materiais;

.técnicos;

. financeiros;

. gerenciais.

. identificação dos valores pessoais e aspirações da gerência sênior;

. reconhecimento das responsabilidades para com a sociedade. 


\section{. Implementação:}

. estrutura organizacional;

. processos organizacionais;

. liderança de topo.

Andrews (1991) ressalta a importância da avaliação dos recursos e competências da empresa, para que seja realizada a adequada associação entre oportunidades de negócio e competências.

Rumelt (1991) fornece um quadro de referência para a avaliação de estratégias de negócios, ressaltando que essa avaliação deverá produzir respostas para as seguintes perguntas:

. Os objetivos do negócio são apropriados?

. Os principais planos e políticas são adequados?

. Os resultados obtidos até o momento confirmam ou refutam os pressupostos básicos da estratégia?

Os testes para avaliação de uma estratégia compreendem quatro critérios básicos:

. consistência, a estratégia tem de apresentar objetivos e políticas consistentes;

. consonância, a estratégia tem de representar uma resposta adaptativa ao ambiente externo e às mudanças críticas nele ocorridas;

. vantagem, a estratégia tem de fomentar a criação ou manutenção de vantagem competitiva no setor de atividade da empresa;

. exeqüibilidade, a estratégia não pode sobreutilizar os recursos disponíveis, nem criar problemas insolúveis.

Abell (1991) critica os textos de planejamento estratégico pelo fato de, em sua maioria, tratarem a definição de negócio como algo implícito no plano. Segundo o autor, até a publicação de seu trabalho a definição de negócio se dava apenas em duas dimensões: produto e mercado.

Segundo o autor, a definição do negócio tem de preceder as demais definições do processo de planejamento estratégico, para que os demais conceitos possam ser explicitamente aplicados.

Seu modelo de negócio compreende três dimensões independentes: 
. as funções do produto/serviço, compreendendo as funcionalidades oferecidas aos clientes pelo produto ou serviço;

. os grupos de clientes, referenciando os conjuntos de clientes para o produto/ serviço;

. as tecnologias utilizadas, fornecendo um referencial de como o produto/serviço é oferecido aos grupos de clientes.

A partir dessa plotagem de um negócio em espaço tridimensional, torna-se muito mais clara e precisa a análise de estratégias básicas, tais como a de foco e diferenciação.

Abell (1991) define precisamente três conceitos chaves para o planejamento estratégico:

. negócio, intersecção de grupos de clientes e funcionalidades baseadas normalmente em tecnologia primária;

. indústria, conjunto de vários negócios, normalmente baseados em uma única tecnologia;

. mercado, intersecção de grupos de clientes e funcionalidades, incluindo todas as tecnologias disponíveis para a prestação desse serviço/oferecimento desse produto.

Porter (1979) apresenta um modelo para a análise de estratégias competitivas em indústrias, baseado nos conceitos de economia industrial e estratégias de negócios. De acordo com o modelo, o potencial de rentabilidade de uma indústria é definido por cinco forças básicas:

. a ameaça de novos entrantes;

. o poder de barganha dos fornecedores;

. a ameaça de produtos/serviços substitutos;

. o poder de barganha dos clientes;

. a intensidade da rivalidade entre os competidores.

Para o autor, o estrategista deverá avaliar cada uma das forças e traçar um plano de ação que incluirá:

. o posicionamento da empresa de forma que as suas capacitações forneçam as melhores defesas contra as forças competitivas e/ou; 
. a influência sobre o equilíbrio de forças na indústria através de movimentos estratégicos, de forma a melhorar a posição competitiva da empresa, e/ou;

. a antecipação de mudanças nos fatores subjacentes às forças e conseqüente resposta a elas, com a esperança de explorar as mudanças através de estratégias apropriadas ao novo equilíbrio competitivo.

Porter (1979) define conceitualmente duas estratégias básicas para a competição: liderança em custo e diferenciação.

Em outra obra, Porter (1985) define o termo cadeia de valor como o conjunto de atividades realizadas por uma empresa para criar valor para os clientes. Essas atividades são física ou tecnologicamente separadas entre si. O autor define sistema de valor como o conjunto de cadeias de valor concatenadas para o fornecimento de produtos/serviços para os clientes finais.

Mintzberg (1991), a partir de uma revisão da literatura sobre estratégias genéricas, propõe um conjunto de cinco grupos de estratégias, organizadas em uma lógica hierarquizada da mais simples até a mais sofisticada:

1. Posicionamento do negócio principal, decisão de se colocar no segmento inicial, médio ou final de um sistema de valor.

2. Definição das características do negócio principal, decisão de enfocar estratégias de obtenção de recursos, produção e/ou disponibilização de produtos/ serviços. Compreende as estratégias de diferenciação (preço, imagem, suporte, qualidade, projeto ou não-diferenciação) e de escopo (segmentação, nicho, customização, ou não-segmentação).

3. Desenvolvimento do negócio principal, decisão de se utilizarem estratégias de penetração em mercados existentes, de desenvolvimento de novos mercados, de expansão geográfica e de desenvolvimento de produtos.

4. Extensão do negócio principal, decisão de se utilizar estratégias de integração de cadeias de valor, de diversificação, de entrada e controle (propriedade total e controle, propriedade parcial e controle idem, controle parcial sem propriedade), estratégias combinadas de integração e diferenciação e estratégias de retirada.

5. Reconcepção do negócio principal, utilização de estratégias de redefinição do negócio, de recombinação do negócio e de relocação do negócio principal.

Visando a contribuir para o rápido alinhamento estratégico de negócios, Hammer (1990) propõe o conceito de reengenharia de processos, apresentando princípios 
básicos a serem aplicados aos processos de negócio, para que estes ocorram com um mínimo de intermediação e perda de energia.

Estes princípios são os seguintes:

. ênfase nos processos associados aos produtos e serviços prestados pela empresa;

. análise multifuncional dos processos;

. obtenção das informações para o processo sempre em sua origem;

. eliminação de atividades intermediárias, que não agregam informação e/ou valor;

. disponibilização das informações para os postos de trabalho de decisão;

. eliminação de controles paralelos; os controles deverão estar contidos no bojo dos próprios processos;

. eliminação das barreiras de tempo e distância através da tecnologia de informação.

Davenport e Short (1990) apresentam direcionamento semelhante, porém trabalham a dimensão estratégica da inovação.

A observação dos princípios, métodos e técnicas detalhados pelos autores permite a verificação de suas origens em alguns textos que o precederam. A reengenharia, como metodologia, é um amálgama de proposições anteriores, de diversas áreas de conhecimento.

Dentre essas, podem ser destacadas as seguintes:

. A questão competitiva, mola mestra para a utilização de reengenharia, relaciona-se com todo um conjunto de trabalhos. Talvez o mais importante seja o de Porter e Millar (1985), que explora a questão da utilização da tecnologia de informação para a obtenção de vantagens competitivas. Merece também citação o trabalho de Stalk Jr. e Hout (1990) sobre competição baseada em tempo.

. A questão da integração das atividades em processos, conforme inicialmente proposta por Martin (1982), em seu trabalho sobre metodologias de planejamento estratégico de informações, origem de sua disciplina de engenharia de informação. O conceito de processo está também fortemente associado à cadeia de valor e ao sistema de valor, conforme definição de Porter (1985).

. A questão da inovação em negócios, tratada por Davis (1987) e por Davis e Davidson (1991). 
. A questão do just-in-time, conforme pode ser visto em Schniederjans (1993), pois tem como princípio a eliminação do trabalho em lotes, para os quais existem estoques de componentes (sejam eles materiais ou informações) e atividades de controle e intermediação, que efetivamente não agregam valor algum aos produtos e serviços a serem disponibilizados para os clientes.

Nogueira, Silberman e Magalhães (1991) analisam em profundidade a associação dos conceitos de reengenharia de processos com os de planejamento de tecnologia de informação e avaliam a sua aplicação no caso da Receita Federal do Brasil.

Nogueira e Amaral (1992), em pesquisa das empresas que operam no Brasil, apresentam e validam um instrumento para avaliar o alinhamento estratégico, a partir do grau de formalização de seu processo e produtos. Em adição, obtêm associações positivas entre a medida de alinhamento (que sumaria a qualidade do processo de alinhamento estratégico) e os resultados econômico-financeiros apresentados por essas mesmas empresas.

\section{Direcionamento para o Futuro}

Davis (1987), propõe um desafiante cenário para a realização de negócios no futuro próximo, operando sob novo paradigma: o oferecimento de produtos e serviços a qualquer hora, em qualquer lugar e de forma imaterial. Sob esse novo paradigma estão sendo construídos os novos negócios, fortemente baseados em conhecimento e em tecnologia de informação.

Davis e Davidson (1991), em trabalho posterior, prevêem que de 1990 até 2010 os negócios baseados em informação irão suplantar, em termos de receitas, lucros e valor de mercado, todas as demais atividades. Os autores fornecem alguns caminhos para a transformação de um negócio tradicional para um baseado em informação, com a aplicação do conceito de turbocharging.

Toffler (1990) aprofunda a questão da informação como principal insumo e produto no novo ambiente de negócios, no qual o cliente passa também a mesclar seu papel com o de produtor, fechando um ciclo que promove a agregação de valor aos serviços e produtos de uma empresa.

Prahalad e Hamel (1990) analisam os resultados de grandes empresas transnacionais no período 1980-1990 e propõem um modelo no qual o principal fator para o sucesso de uma organização está em suas competências básicas. Competência básica é definida como sendo a capacidade apreendida por um gru- 
po de elementos de uma organização, para coordenar esforços de produção e integrar diferentes tecnologias.

Hamel e Prahalad (1994) analisam o desafio da competitividade em três níveis:

. O primeiro nível corresponde a reestruturação de portfólio e de downsizing, normalmente ações rápidas e que levam as organizações a reduzir seu porte e seus custos.

. O segundo nível corresponde à reengenharia de processos e à melhoria contínua, que permitem às organizações realizar as atuais atividades de forma mais eficiente.

. O terceiro nível corresponde à reinvenção da indústria e à regeneração das estratégias, possibilitando às organizações a construção de seu futuro.

$\mathrm{Na}$ visão dos autores, a gênese das corporações tem início a partir de suas competências básicas, passa pela tangibilização dessas competências, na forma de produtos básicos, que vem a compor o conceito de negócios, nos quais as empresas irão oferecer seus produtos finais.

Essa abordagem remete diretamente à terceira dimensão defendida por Abell (1991), que contempla efetivamente a questão tecnológica, tanto em termos de produto quanto de processo.

Visando a avaliar o grau de direcionamento para o futuro de uma empresa, Hamel e Prahalad (1994) oferecem em sua obra, um conjunto de questões para serem respondidas pelos executivos. $\mathrm{O}$ instrumento utilizado nesta pesquisa foi baseado nessas questões.

\section{Gestão de Tecnologia de Informação}

Benjamin et al. (1984) sinalizam a necessidade de mudança da área de sistemas de informação para assumir o escopo mais amplo da tecnologia de informação (T.I.). Segundo esses autores, a tecnologia da informação apresenta grande potencial para gerar oportunidades e vantagens competitivas aos negócios, mas poucas empresas se apercebem disso.

Porter e Millar (1985) analisam o potencial da T.I. na geração de vantagens competitivas. Eles verificam, através da aplicação do modelo de análise de indústrias de Porter, que a T.I. tem capacidade de alterar tanto o processo produtivo em si, como também as relações das empresas com seus fornecedores clientes e competidores. 
Bakos e Treacy (1986) identificam fatores que inibem a utilização do potencial estratégico da T.I.:

. resistência à inovação e mudança por parte das organizações;

. inexistência da necessidade de obter vantagens competitivas;

. desconhecimento das oportunidades em tecnologia da informação;

. pouca comunicação entre as áreas de empresa, principalmente entre a área de sistemas e o resto da empresa;

. falta de instrumentos para quantificar os benefícios de projetos de T.I.

Synnott (1987) define a diferença entre a era do computador (décadas de 60 e 70) e a era da informação (décadas de 80 e 90) deste modo:

. a era do computador era caracterizada pela utilização da tecnologia com o objetivo de redução de custos operacionais;

. a era da informação caracteriza-se pela utilização da T.I. não somente como instrumento de redução de custos, mas principalmente como alavancador de receitas. Essas receitas adviriam de novos produtos e serviços, novos canais de fornecimento e de distribuição.

Em conformidade com o exposto, o autor reforça a necessidade de o planejamento estratégico do negócio e de o planejamento de tecnologia de informação serem realizados de forma integrada e interativa.

Johnston e Carrico (1988) sugerem que o ambiente competitivo da indústria influencia o posicionamento estratégico da empresa. Segundo eles, quanto maior a competitividade da indústria na qual se insere, maior o esforço da empresa em posicionar estrategicamente a área de T.I.

Esses autores, em função do posicionamento estratégico de T.I., definem três grupos de empresas:

. a área de T.I. apóia as operações da empresa, porém não está estrategicamente integrada a ela;

. a área de T.I. apóia a estratégia, porém não participa de sua concepção;

. a área de T.I. faz parte do grupo estratégico da empresa. Dessa forma, a empresa utiliza a T.I. na criação de novos produtos e serviços, no relacionamento com clientes e fornecedores, etc. 
Para Venkatraman (1991), não tem sentido discutir se a T.I. é estratégica. A questão passa a ser: Como utilizar a T.I. na administração estratégica, ou ainda melhor: Como alinhar T.I. e estratégia?

O autor estabelece cinco níveis de reconfiguração estratégica do negócio, baseados na utilização da tecnologia da informação. Esses níveis estão em escala crescente de intensidade de transformação do negócio e de benefícios potenciais. Os níveis são os seguintes:

. exploração localizada: a utilização da T.I. em áreas funcionais da empresa;

. integração interna: a utilização da T.I., integrando áreas funcionais da empresa;

- redesenho dos processos do negócio: o efetivo redesenho dos processos de negócio, tirando o máximo proveito da T.I.;

.redesenho da rede do negócio: o redesenho dos processos de negócio, integrando clientes, fornecedores e outros agentes externos à empresa;

. redefinição do escopo do negócio: a partir das possibilidades da T.I., o próprio escopo dos serviços e produtos da empresa pode ser ampliado.

Existe claro paralelismo entre esse quadro e o de estratégias genéricas proposto por Mintzberg (1991), o que reforça a integração entre tecnologia gerencial e tecnologia de informação.

Nogueira e Ferreira (1996) desenvolveram, aplicaram e validaram um instrumento para a apreciação do alinhamento da área de tecnologia de informação em relação à estratégia empresarial, tendo verificado, nessa pesquisa exploratória, a associação positiva entre o alinhamento estratégico e a satisfação da empresa com os serviços da área de tecnologia de informação.

\section{Administração de Recursos Humanos}

Kanter (1993) questiona a tímida postura das empresas em face das mudanças. A partir da análise de 115 empresas inovadoras, a autora relaciona as condições e estruturas organizacionais favoráveis ao surgimento de inovações:

. a organização providencia os sistemas, normas, cultura e recompensas de forma a incentivar as pessoas a serem empreendedoras, solucionarem problemas, enxergarem e aproveitarem oportunidades; 
. a organização tem uma estrutura formada de pequenas equipes de trabalho. As equipes são autônomas e completas, ou seja, possuem representantes de todas as funções necessárias à realização de suas tarefas;

. a organização possui uma cultura de orgulho, ao invés de uma cultura de mediocridade ou inferioridade.

Peters (1987) afirma não mais existir, para mercados de massa, ambiente estável e previsível. Para sobreviver é fundamental ser flexível e estar habilitado para as mudanças. Também ataca a complacência gerencial, exigindo qualidade, flexibilidade e treinamento do mais alto nível.

O autor destaca cinco pontos a serem perseguidos:

. obsessão com o atendimento aos clientes;

. constante inovação, estimulando riscos e aceitando algumas falhas;

. participação: obter flexibilidade, atribuindo autoridade às pessoas;

. liderança que goste de mudança e compartilhe uma visão inspiradora;

. sistemas de apoio, destinados a medir: freqüência de inovação, derrubada de divisórias, qualidade, treinamento e ritmo de mudança.

Ainda segundo o autor, os fatores que favorecem essa postura são:

. direção: núcleo central com ampla variedade de pessoas que ajudem a criar e desenvolver a visão empresarial;

. remuneração: os funcionários devem ser pagos para agir rapidamente e constantemente aperfeiçoar tudo o que é feito;

. integração: deve apresentar alto grau de interação interna e externa com fornecedores e clientes;

. cultura: que busque constantemente o aperfeiçoamento em tudo;

- postura gerencial: trabalho árduo, mantendo clara a visão, vivenciando a visão, perambulando, mantendo diálogo, escutando e continuamente treinando.

Segundo Waterman Jr. (1987) as empresas que desejarem sobreviver devem tornar-se renováveis. Isto significa possuir:

. oportunismo informado: informação como vantagem competitiva e flexibilidade como arma estratégica; 
. estrutura organizacional: onde todos contribuam criativamente na solução dos problemas;

. controles gerenciais compatíveis;

. dirigentes com visão do todo;

. trabalho em equipe;

. capacidade de converter grandes idéias em pequenas ações;

. atenção visível do gerente nas tarefas a serem realizadas;

. hábito de quebrar o hábito.

Davenport (1993) estabelece os pontos para promover a inovação na empresa através da informação, da tecnologia e do gerenciamento dos recursos humanos. Dentre os habilitadores organizacionais e de recursos humanos temos:

. trabalho em equipes multifuncionais;

. cultura participativa, com delegação de poderes e participação nas decisões;

.treinamento constante;

. motivação, remuneração e avaliação que incentivem e recompensem uma postura individual ativa nos processos de mudança.

\section{Metodologia}

\section{A Pergunta da Pesquisa}

Esta pesquisa tem como objetivo verificar a influência do grau de formalização do processo de planejamento, do alinhamento da área de tecnologia de informação e do alinhamento da área de recursos humanos sobre o direcionamento da empresa para o futuro.

Em outras palavras, quais desses elementos efetivamente estão presentes nas empresas que estão construindo as competências que deverão possibilitar a sobrevivência e o seu crescimento no futuro? 


\section{As Hipóteses}

De acordo com a literatura, foi montado um modelo de path analysis, conforme definido por Asher (1976) e Hair (1995), o qual origina o seguinte conjunto de hipóteses:

1. Verifica se o alinhamento da tecnologia de informação é influenciado pelo grau de formalização do planejamento das empresas.

2. Verifica se o alinhamento dos recursos humanos é influenciado pelo grau de formalização do planejamento e pelo nível de alinhamento de tecnologia de informação das empresas.

3. Verifica se o direcionamento para o futuro é influenciado pelo grau de formalização do planejamento, pelo nível de alinhamento de tecnologia de informação e pelo grau de alinhamento dos recursos humanos das empresas.

\section{As Variáveis}

Para responder às hipóteses formuladas, foram operacionalizadas as seguintes variáveis:

. Nível de Formalização do Processo de Planejamento: medida através de 21 itens do questionário, baseados no instrumento para o alinhamento estratégico, proposto e validado por Nogueira e Amaral (1992).

. Direcionamento para o Futuro: operacionalizado através de 27 itens, baseados nas proposições de Hamel e Prahalad (1994).

. Alinhamento dos Recursos Humanos: medido através de 12 questões, baseadas nos conceitos propostos por Kanter (1983), Peters (1987), Waterman Jr. (1987) e Davenport (1993).

. Alinhamento da Tecnologia de Informação: com 10 itens, conforme foram utilizados por Nogueira e Ferreira (1996).

. Faturamento, Patrimônio Líquido, Lucro Líquido, Número de Empregados em 1994 e 1995, conforme publicados pela edição Maiores e Melhores da revista Exame $(1995,1996)$.

\section{A Coleta dos Dados}

O instrumento da pesquisa foi aplicado a executivos de 25 empresas de grande porte, ao final de um seminário durante o qual foram tratados os tópicos por ele cobertos. 


\section{Procedimentos para a Análise dos Dados}

As respostas dos questionários e os dados financeiros foram analisados pelo software SPSS (1975), através dos seguintes procedimentos:

. análise descritiva: média e desvio padrão;

. confiabilidade e validade das variáveis: reliability e correlação simples de Pearson;

. determinação dos fatores componentes das variáveis: análise fatorial;

. teste das hipóteses: path analysis, conforme proposto por Asher (1976) e Hair (1995), operacionalizado através do procedimento de regressão linear múltipla;

. análise de correlação entre as variáveis e os dados financeiros: correlação simples de Pearson.

\section{Resultados}

\section{As Empresas Participantes da Pesquisa}

\begin{tabular}{|l|c|c|c|c|c|}
\multicolumn{2}{r}{ Ouantidade } & Faturamento & PL & Lucro & Funcionários \\
\hline Públicas & 16 & 1.465 & 4.612 & 108 & 12.512 \\
\hline Privadas & 9 & 2.180 & 1.401 & 84 & 5.695 \\
\hline Total & 25 & 1.751 & 3.327 & 98 & 9.785 \\
\hline
\end{tabular}

Os valores acima representam a média obtida para os dados de 1995 para as empresas pesquisadas. A partir deles e de seus correspondentes para o ano anterior, 1994, observamos os seguintes fatos:

. O faturamento das empresas privadas pesquisadas era $50 \%$ superior, em média, ao das empresas públicas participantes, apresentando $58 \%$ menos funcionários (54\% em 1995) e um patrimônio líquido 69\% inferior (70\% em 1995) ao das empresas públicas participantes.

. O nível de faturamento das empresas pesquisadas subiu, de 1994 para 1995, praticamente na mesma razão (11\% nas públicas e $10 \%$ nas privadas).

.Em relação à lucratividade, verifica-se efeitos diametralmente opostos: crescimento de $38 \%$ em média para as empresas públicas, enquanto as privadas apresentam redução de $24 \%$. 
. O patrimônio líquido se comportou de forma equivalente para ambas, subindo $14 \%$ em média nas públicas e $10 \%$ nas privadas.

. O número de funcionários foi reduzido em cerca de $5 \%$ nas empresas públicas, e cresceu $3 \%$ nas privadas.

Sem maiores sofisticações analíticas, esses resultados mostram que, para as empresas participantes ocorreram sensíveis ajustes em suas atividades durante o período analisado:

. As empresas privadas, por conta do acirramento da competição interna e externa, tiveram suas margens de lucro reduzidas sensivelmente, porém não dispensaram funcionários.

. As empresas públicas tiveram suas tarifas realinhadas, recompondo assim sua lucratividade. Além disso, iniciaram uma modesta redução em seus quadros de pessoal.

\section{Análise das Variáveis}

\section{Formalização do Processo de Planejamento}

Proveniente do desmembramento do instrumento de Nogueira e Amaral (1992), essa medida foi composta por 21 itens, que avaliaram o grau de formalização do processo de planejamento e do próprio plano produzido por ele.

A medida apresentou-se confiável, com o coeficiente Alpha de Crombach de 0,92 e com a validade indicada através da correlação de 0,84 significante a $p<0,001$, entre a medida e $\mathrm{o}$ item de controle. A análise fatorial determinou 4 fatores, explorados a seguir, que explicaram $71 \%$ da variância total.

\section{Direcionamento para o Futuro}

Essa variável foi composta por 27 itens do questionário, tendo apresentado o coeficiente Alpha de Crombach de 0,94 e com a validade indicada através da correlação da variável com a pergunta de controle apresentando o valor de 0,80 significante a $\mathrm{p}<0,001$. A análise fatorial determinou 4 fatores, analisados a seguir, que explicaram $76 \%$ da variância total.

. O primeiro fator está associado ao comprometimento da empresa com o futuro através das ações praticadas no curto prazo e do conhecimento do potencial da empresa. Esse fator foi denominado Consciência. Pode ser observado que a maior parte dos itens desse fator obtiveram pontuação média, em relação à escala de sete pontos utilizada. Uma possível interpretação para esse fato po- 
deria ser a dificuldade dos executivos no tratamento de questões efetivamente estratégicas, num horizonte de tempo não usual para eles. Nessa linha de raciocínio, pode ser notado que os itens relacionados ao momento presente (competências, satisfação dos clientes e produtos pioneiros) possuem as maiores pontuações, enquanto o item do horizonte de longo prazo apresentou a menor média.

. O segundo fator, denominado Criando o Novo, apresenta pontuações mais altas do que o fator anterior, talvez por representar o aspecto das ameaças e inquietações das empresas em face do futuro turbulento. Os itens que representam ações efetivas apresentaram as mais baixas médias. A partir de outra análise, foi verificado que o item Urgência em Reinventar o Negócio obteve as maiores pontuações nas empresas públicas.

. O terceiro fator, denominado Médio Prazo, revela a compreensão de que haverá radicais mudanças no caminho para o futuro e que, de alguma maneira, as empresas tentam buscar novas receitas e produtos, além de aproveitar novas oportunidades; porém a dedicação dos executivos às questões estratégicas é insuficiente.

. O quarto e último fator, denominado Visão, indicou que os executivos têm um esboço de visão, tanto para o horizonte de 5 anos quanto para o de 10.

\section{Alinhamento dos Recursos Humanos}

Essa variável foi composta por 12 itens do questionário, tendo apresentado alto nível de confiabilidade, com o coeficiente Alpha de Crombach de 0,93 e com a validade demonstrada através da correlação da variável com a pergunta de controle apresentando o valor de 0,86 significante a $p<0,001$. A análise fatorial determinou 2 fatores, que explicaram $70 \%$ da variância total. Foram denominados Dimensão do Indivíduo e Dimensão da Empresa.

. Na dimensão do indivíduo foi verificado o direcionamento para um perfil autônomo e empreendedor, associado ao investimento das empresas em programas de desenvolvimento de recursos humanos.

- Na dimensão da empresa foram encontradas as médias mais baixas de todo o instrumento, revelando que a organização ainda não está pronta para recrutar e manter os profissionais com o perfil desejado.

\section{Alinhamento da Tecnologia de Informação}

Essa variável foi composta por 10 itens do questionário, tendo apresentado alto nível de confiabilidade, com o coeficiente Alpha de Crombach de 0,86 e com a 
validade demonstrada através da correlação da variável com a pergunta de controle apresentando o valor de 0,67 significante a $p<0,001$. A análise fatorial determinou 3 fatores, que explicaram $82 \%$ da variância total:

. O primeiro, denominado Planejamento dos Investimentos, indicou que a T.I. está viabilizando a estratégia nas empresas e que os investimentos em T.I. estão mais voltados para a reengenharia de processos do que para uma inovação em negócios ou tecnologia.

. O segundo, denominado Importância Percebida pela Organização, sugere uma postura coadjuvante da área de T.I. no processo de planejamento estratégico das organizações.

. O terceiro fator, denominado Infraestrutura dos Serviços/Produtos de T.I., sugere uma postura modesta da área de T.I. sob a ótica da sua contribuição para os negócios das empresas.

\section{Teste das Hipóteses}

\begin{tabular}{|c|c|c|c|c|}
\hline & & $\begin{array}{l}\text { FORMALIZAÇÃo } \\
\text { PLANEJAMENTO }\end{array}$ & $\begin{array}{c}\text { ALINHAMENTO DE } \\
\text { T.I. }\end{array}$ & $\begin{array}{c}\text { ALINHAMENTO DE } \\
\text { R.H. }\end{array}$ \\
\hline ALINHAMENTO DE T.I. & $\begin{array}{l}\mathrm{b} \\
\mathrm{n} \\
\mathrm{sig} \\
\end{array}$ & $\begin{array}{c}0,62 \\
(20) \\
p<0,01 \\
\end{array}$ & & \\
\hline $\begin{array}{l}\text { ALINHAMENTO DE } \\
\text { R.H. }\end{array}$ & $\begin{array}{l}\mathrm{b} \\
\mathrm{n} \\
\mathrm{sig} \\
\end{array}$ & $\begin{array}{c}0,87 \\
(20) \\
\mathrm{p}<0,001 \\
\end{array}$ & n.s. & \\
\hline $\begin{array}{l}\text { DIRECIONAMENTO } \\
\text { PARA O FUTURO }\end{array}$ & $\begin{array}{l}\mathrm{b} \\
\mathrm{n} \\
\mathrm{sig}\end{array}$ & n.s. & $\begin{array}{c}0,39 \\
(17) \\
p<0,02 \\
\end{array}$ & $\begin{array}{c}0,77 \\
(17) \\
\mathrm{p}<0,01\end{array}$ \\
\hline
\end{tabular}

De acordo com os coeficientes encontrados, a existência de um processo formal de planejamento não é pré-condição, nem fomenta o direcionamento para o futuro.

Também é notado que o planejamento de tecnologia de informação não está alinhado com o de recursos humanos. Esse ponto é grave, pois no redirecionamento das empresas para o futuro, tanto o alinhamento de recursos humanos quanto o de T.I. são componentes fundamentais. Essa afirmação está apoiada exatamente pelas correlações significativas apresentadas na última linha da tabela acima.

\section{Correlação das Variáveis com Indicadores}

Foi observado que o direcionamento para o futuro ocorre com maior intensida- 
de nas empresas de maior faturamento e número de funcionários. É interessante notar que não foi obtida relação com a lucratividade, o que é coerente, uma vez que o direcionamento para o futuro não produz resultados imediatos e sim a médio e longo prazo.

O alinhamento de T.I. aparece associado ao patrimônio líquido das empresas estudadas, e o alinhamento de R.H. não apresenta relação alguma com medidas de porte ou desempenho.

\section{Conclusão}

O objetivo dessa pesquisa exploratória foi analisar o fenômeno do direcionamento das empresas para o futuro, verificando a associação deste direcionamento com a postura em recursos humanos, tecnologia de informação e planejamento.

Para tal, foi revista a literatura sobre cada um dos tópicos envolvidos, assim como foram desenvolvidas medidas que compuseram um instrumento para avaliálos.

O instrumento foi aplicado a executivos de 25 empresas, públicas e privadas, que participaram de um seminário internacional sobre o tema.

Todas as medidas tiveram sua validade e confiabilidade testadas, tendo sido consideradas adequadas à natureza da pesquisa.

Com relação ao processo e ao produto do planejamento das empresas, foi verificada ênfase no planejamento, na formalização de projetos e menor peso na aferição de resultados e na responsabilização dos profissionais envolvidos com eles. Esse resultado é semelhante ao obtido por Nogueira e Amaral (1992).

As perguntas relacionadas com o direcionamento para o futuro indicaram que os executivos esperam radicais mudanças no contexto dos negócios e têm grande ansiedade quanto a isso; porém, por outro lado, não confiam na visão definida pela empresa para o futuro e, ainda mais, dedicam às questões estratégicas muito menos tempo do que consideram necessário.

Esses resultados são alarmantes, pois sem visão, sem tempo dedicado a produzi-la ou ajustá-la, fica muito difícil, se não impossível, o desenvolvimento das ações necessárias à sobrevivência no médio e longo prazo das empresas.

No tocante à administração dos recursos humanos, as empresas participantes vislumbram um novo perfil desejado, investem em desenvolvimento, porém não 
apresentam sistemas de recrutamento, seleção, remuneração e avaliação coerentes com a nova situação desejada.

A área de tecnologia de informação apresentou-se como apoio ao planejamento estratégico, contribuindo de forma passiva no direcionamento para o futuro.

Do teste das hipóteses pode ser verificado que:

. a formalização do processo de planejamento influencia positivamente o alinhamento de T.I e de R.H, com maior ênfase no último;

. o alinhamento de T.I. não influencia o de R.H.;

. o direcionamento para o futuro é influenciado fortemente pelo alinhamento de

R.H. e de forma modesta pelo de T.I.

Desses resultados pode ser concluído que, para as empresas pesquisadas, os fatores que influenciam o direcionamento para o futuro são o alinhamento dos recursos humanos e, em menor escala, o alinhamento da tecnologia de informação.

Também é importante notar que o fato de haver um processo formal de planejamento empresarial não é relevante para o direcionamento para o futuro. Em outras palavras, possuir plano, orçamento e outros produtos não garante que o processo de planejamento tenha efetivamente endereçado as questões chaves para a construção do futuro da empresa.

Coerentemente, de acordo com os resultados, para que ocorra o direcionamento para o futuro faz-se necessário que a empresa possua recursos humanos com o perfil autônomo empreendedor, e que também ela os desenvolva, avalie e remunere coerentemente.

Nota-se também que o alinhamento da área de T.I. não influencia o de R.H., indicando que o redesenho de processos e postos de trabalho, item de fundamental importância no reposicionamento das empresas, não está sendo devidamente realizado.

O direcionamento para o futuro é um fenômeno encontrado principalmente nas empresas de elevado faturamento e número de empregados. São elas as que mais demonstram preocupação com o desenvolvimento de uma visão de longo prazo, através da qual poderão se reposicionar e desenvolver as competências necessárias à sobrevivência no futuro.

Para tal elas necessitam desenvolver processos orgânicos e completos de alinhamento estratégico, que integrem, através de visão objetiva e compartilhada, vetores estratégicos, que envolvam todos os segmentos de competência, integran- 
do recursos humanos, de tecnologia, clientes, fornecedores e parceiros, de forma objetiva e responsável.

Esta pesquisa, de natureza exploratória não permite a generalização de seus resultados para quaisquer empresas dos diversos setores de atividade. Para tal, é sugerido aos pesquisadores da área que realizem um procedimento amostral e repliquem esse trabalho nos diversos setores de atividade.

\section{ReferênCias Biblográficas}

\section{ABELL, D. F.}

Defining the business : the starting point of strategic planning. Englewood Cliffs, NJ : Prentice-Hall, 1991. p. 169-190.

ANDREWS, K. R.

The concept of corporate strategy. In: The strategy process: concepts, contexts and cases. 2. ed. Englewood Cliffs, NJ : Prentice-Hall, 1991. p. 44-52.

ASHER, H. B.

Causal modeling. London : Sage, 1976.

BAKOS, Y. J.;

TREACY M. E.

Information technology and corporate strategy : a research perspective. MIS Quarterly, Jun. 1986.

BENJAMIN, R. I. et al.

Information technology : a strategic opportunity. Sloan Management Review, Spring 1984.

DAVENPORT, T. H.

Process innovation. Boston : Harvard Business School Press, 1993.
DAVENPORT, T. H.;

SHORT, J. E.

The new industrial engineering : information technology and business process redesign. Sloan Management Review, v. 31, n. 4, p. 11-26, Summer 1990.

DAVIS, S. M.

Future perfect. Reading, MA : Addison Wesley, 1987. cap. 5.

DAVIS, S. M.;

DAVIDSON, W. H.

2020 vision. New York : Simon \& Schuster, 1991. cap. 4

EXAME.

Maiores e melhores. ago. 1995.

EXAME.

Maiores e melhores. ago. 1996.

HAIR, J. F. et al.

Multivariate data analysis. Englewood Clifs, NJ : PrenticeHall, 1995.

HAMEL, G.;

PRAHALAD, C. K.

Competing for the future. Boston: Harvard Business School Press, 1994. p. 01-25. 
HAMMER, M.

Reengineering work : don't automate, obliterate. Harvard Business Review, v. 68, n. 4, p. 104-112, Jul./Aug. 1990.

JOHNSTON, H. R.;

CARRICO, S. R.

Developing capabilities to use information strategically. MIS Quartely, v. 12, n. 1, p. 37-47, Mar. 1988.

KANTER, R. M.

The change masters. New York : Simon and Shuster, 1983.

MARTIN, J.

Strategic data-planning methodologies. Englewood Cliffs, NJ : Prentice-Hall, 1982.

MINTZBERG, $\mathrm{H}$.

Generic strategies. In:

The strategy process : concepts, contexts and cases. 2. ed. Englewood Cliffs, N J : PrenticeHall, 1991.

NIE, N. H. et al.

SPSS : statistical package for the social sciences. New York : McGraw-Hill, 1975.

NOGUEIRA, A. R. R.;

AMARAL, T. M.

O processo de planejamento para a utilização estratégica da tecnologia da informação : um estudo exploratório. In: XVI ENCONTRO ANUAL DA ANPAD (1992 : Canela). Anais ... Canela : ANPAD, 1992.

NOGUEIRA, A. R. R.;

FERREIRA, M. G.

Terceirização de serviços de tecnologia de informação : um estudo em bancos comerciais privados. In: XX ENCONTRO ANUAL DA ANPAD (1996 : Angra dos Reis). Anais ... Angra dos Reis : ANPAD, 1996.

NOGUEIRA, A. R. R.;

SILBERMAN, C.;

MAGALHÃES, M. A.

Planejamento de sistemas de informação : uma oportunidade para o reprojeto dos processos da organização. Relatório COPPEAD 256, Rio de Janeiro, 1991.

PETERS, T.

Thriving on chaos. New York : Alfred A. Knopt, 1987.

PORTER, M. E.

How competitive forces shape strategy. Harvard Business Review, Mar/Apr. 1979.

Competitive advantage. New York: Free Press, 1985.

PORTER, M. E.;

MILLAR, V. E.

How information gives you competitive advantage. Harvard Business Review, Aug. 1985.

PRAHALAD, C. K.;

HAMEL, G.

The core competence of the corporation. Harvard Business Review, p. 79-91, May/June 1990.

QUINN, J. B.

Strategies for change. In: MINTZBERG, $H$. The strategy process : concepts, contexts and cases. 2. ed. Englewood Cliffs, NJ : Prentice-Hall, 1991. p. 0412. 
RUMELT, R.

The evaluation of business strategy. In : MINTZBERG, H. The strategy process : concepts, contexts and cases. 2. ed. Englewood Cliffs, NJ : PrenticeHall, 1991. p. 52-59.

SCHNIEDERJANS, M. J.

Topics in just-in-time management. Boston : Allyn e Bacon, 1993.

STALK JR., G. S.;

HOUT, T. M.

Competing against time. New York : Free Press, 1990.

SYNNOTT, W. R.

The information weapon : winning customers and markets with technology. New York : John Wiley \& Sons, 1987.

TOFFLER, A.

Powershift : knowledge, wealth and violence at the edge of the 21 st. century. New York : Bantam, 1990.

VENKATRAMAN, N.

IT induced business reconfiguration. In: The corporation of the 1990s : information technology and organizational transformation. New York : Oxford University Press, 1991. p. 122-158.

WATERMAN JR., R. H.

The renewal factor. New York :

Bantam, 1987. 